\title{
Application of chloroplast promoters of Cyanidioschyzon merolae for exogenous protein expression
}

\author{
Tomasz Krupnik, Wioleta Wasilewska, Anna Drożak, Elżbieta Romanowska and \\ Maksymilian Zienkiewicz*
}

Faculty of Biology, University of Warsaw, Miecznikowa 1, 02-096 Warszawa, Poland

The ability to transform the chloroplast of Cyanidioschyzon merolae was limited by lack of confirmed and reliable promoter sequences (among other reasons), capable of delivering stable or modulated DNA transcription followed by protein synthesis. Our research has confirmed the applicability of three selected chloroplast promoters in C. merolae chloroplast overexpression of the exogenous protein (i.e., chloramphenicol acetyltransferase) and genetic transformation. These results might facilitate further research on genetically modified strains of $C$. merolae to envisage yet unknown aspect of cellular and plastic physiology as well as C. merolae potential applications as bio-factories or sources of useful chemicals.

Key Words: chloroplast promoters; chloroplast transformation; Cyanidioschyzon merolae

\section{INTRODUCTION}

Cyanidioschyzon merolae is a eukaryotic, extremophilic, red alga which thrives at low $\mathrm{pH}$ (approximately 0.2 to 4) environment and moderately high temperature (40$56^{\circ} \mathrm{C}$ ). In recent years, this organism has gained much attention thus becoming a new model eukaryote for cell and organelle biology research (Kuroiwa et al. 2017). The newly developed methods of genetic transformation of the nuclear (Zienkiewicz et al. 2018) and the chloroplast genome (Zienkiewicz et al. 2017b) might enable a broad range of possible research in physiology and biotechnology. The prospect of expression of recombinant proteins in the chloroplast has attracted considerable attention as chloroplast may accumulate considerable quantities of protein (Maliga 2004, Bock 2007, Daniell et al. 2009). The accumulation of protein in chloroplasts may reach as much as $70 \%$ of the total soluble protein in a leaf of the cell (Daniell et al. 2009, Zienkiewicz et al. 2017b). Introduction of exogenous genes expression into the chloroplast genome requires a host promoter, either constitutive or inducible. Until recently there were no reliably identified promoter sequences useful in chloroplast transformation.

Here, we have investigated the practical applicability of three selected chloroplast promoters for stable and highly efficient overexpression of recombinant proteins in C. merolae chloroplasts. We have selected three gene promoters, previously (Kanesaki et al. 2012) identified as dependent on the light irradiance $\left(\mathrm{P}_{\mathrm{psbD}}\right.$-promoter of the photosystem II D2 protein, gene $p s b \mathrm{D}$ [CMV081C]), dependent on the cell cycle $\left(\mathrm{P}_{\mathrm{rbcL}}-\right.$ promoter of the Ribulose-1,5-bisphosphate carboxylase / oxygenase [RuBis$\mathrm{CO}$ ] large chain, gene $r b c \mathrm{~L}$ [CMV013C]) as well as mostly
(9) $\$$ This is an Open Access article distributed under the terms of the Creative Commons Attribution Non-Commercial License (http://creativecommons.org/licenses/by-nc/3.0/) which permits unrestricted non-commercial use, distribution, and reproduction in any medium, provided the original work is properly cited.
Received August 1, 2018, Accepted December 5, 2018

*Corresponding Author

E-mail: maximus@biol.uw.edu.pl

Tel: +48-22-554-3912, Fax: +48-22-554-3910 
constitutive promoter ( $\mathrm{P}_{\text {dnak }}$ of a Hsp70-type chaperone, gene dnaK [CMV163C]).

Chloramphenicol acetyltransferase (CAT) is a wellknown (Shaw and Unowsky 1968) antibiotic resistance enzyme. It was first described as a resistance factor in Enterobacteriaceaea and its enzymatic activity is to facilitate catalysis deactivation of chloramphenicol by formation of 3-acetoxy chloramphenicol, a derivative incapable of binding with the $50 \mathrm{~S}$ bacterial or chloroplast ribosome unit. Chloramphenicol blocks protein chain elongation by inhibiting the peptidyl transferase activity of the bacterial ribosome in the 23S rRNA of the 50S subunit. This antibiotic does not bind to eukaryotic ribosomes localized in cytosol nor in mitochondria due to lack of the 50S unit. However, chloroplast ribosomes do possess the 50S units considered to be similar enough, with those found in bacteria, to be potentially sensitive to chloramphenicol (Zienkiewicz et al. 2017b).

\section{MATERIALS AND METHODS}

\section{Cell cultures}

Cyanidioschyzon merolae, 10D (NIES-1332, unialgal, clonal, and non-axenic) strain was obtained from Microbial Culture Collection (http://mcc.nies.go.jp; Tsukuba, Japan) and was used throughout this study. Cells were grown in MA2 liquid medium (Minoda et al. 2004) in a glass vessel shaken at $100 \mathrm{rpm}$ under continuous white light illumination $\left(100 \mu\right.$ moles photon $\left.\mathrm{m}^{-2} \mathrm{~s}^{-1}\right)$ at $37^{\circ} \mathrm{C}$ or on Petri dishes filled with MA2 medium, solidified by addition of $0.4 \%$ gellan gum (Phytagel; Sigma-Aldrich, Munich, Germany) (Minoda et al. 2004) or 0.75\% agar (Basica LE, Prona, EU).

Escherichia coli, strain DH5 $\alpha$ (genotype: F- 880lacZ $\Delta \mathrm{M}$ $15 \Delta$ (lacZYA-argF) U169 recAl endAl hsdR17 (rK-, mK+) phoA supE44 $\lambda$ - thi- 1 gyrA96 relA1) were used for construction of transformation vectors (Hanahan 1983). Bacterial cells were cultured in liquid Luria-Bertani (LB) medium ( $1 \%$ Bacto tryptone, $0.5 \%$ yeast extract, $1 \% \mathrm{NaCl}$ at $37^{\circ} \mathrm{C}$ ) or on Petri dishes with LB medium solidified by addition $1 \%$ agar. For selecting of transformed cells, the medium was supplemented with Kanamycin $\left(30 \mu \mathrm{gLL}^{-1}\right)$.

\section{Escherichia coli competent cells}

Preparation of E. coli competent cells and transformation was carried out as described earlier (Sambrock et al. 1989). Electrocompetent cells were prepared according to manufacturer instructions of GenePulser apparatus (Bio-Rad, Hercules, CA, USA).

\section{Construction of plasmids}

The detailed construction of the pCCATCH plasmid $(12,455$ bp, GeneBank accession No. KX056487) containing cat $\mathrm{CH}$ gene, driven by dnaK promoter region $(1,085$ bp in size, coordinates 106,558-107,643 bp) has been previously described by Zienkiewicz et al. (2017b). The pCCATCHD (12,153 bp) and pCCATCHL (11,916 bp) are identical to pCCATCH with cat $\mathrm{CH}$ gene driven by promoter regions of $p s b \mathrm{D}$ gene (780 bp in size, coordinates $51,736-52,515 \mathrm{bp}$ ) or $r b c \mathrm{~L}$ gene (543 bp in size, coordinates $6,960-7,503 \mathrm{bp}$ ), respectively. Similarly, as in the case of dnaK promoter, $p s b \mathrm{D}$ and $r b c \mathrm{~L}$ promoter regions were introduced into transformation plasmid molecules by pairs of primers with SalI and KpnI restriction enzymes sites. Coordinates refer to chloroplast molecule accession No. AB002583.1. The name of pCCATCH plasmid has been converted into pCCTACHK to indicate the use of the $d n a \mathrm{~K}$ gene promoter region for $c a t \mathrm{CH}$ gene expresion.

Plasmid pCCATGN (13,770 bp) was used as a control in indirect immunofluorescence and fluorescence microscopy. Its construction was described before (Zienkiewicz et al. 2017a).

All primers used in this study were listed in Supplementary Table S1.

\section{Enzymatic manipulations of DNA}

All enzymatic manipulations of DNA, such as restriction digestion, blunting of cohesive termini using T4 polymerase, the Klenow fragment or ligation reaction were performed according to protocols supplied by the manufacturers.

\section{Polymerase chain reaction}

Polymerase chain reactions (PCRs) were performed according to manufactures protocols, supplied with the Phire Plant Direct PCR kit containing, Plant Phire Hot Start II DNA Polymerase or DreamTaq DNA polymerase (Thermo Fisher Scientific Inc., Waltham, MA, USA).

\section{Plasmid DNA purification and transformation of Cyanidioschyzon merolae}

Plasmid DNA purification was performed with the Ex- 
tractme Plasmid DNA Kit, Gdańsk, Poland. Polyethylene glycol (PEG)-mediated transfections were performed as described before (Ohnuma et al. 2008) with the following modifications. A freshly started, overnight grown 100 $\mathrm{mL}$ of $C$. merolae culture at $\mathrm{OD}_{750} 0.4$ was spun down at $2,000 \times \mathrm{g}$ for $5 \mathrm{~min}$ in $40^{\circ} \mathrm{C}$ in a table-top centrifuge (5810 $\mathrm{R}$; Eppendorf, Hamburg, Germany) and resuspended in $100 \mathrm{~mL}$ of MA-I buffer $\left(20 \mathrm{mM}\left[\mathrm{NH}_{4}\right]_{2} \mathrm{SO}_{4}, 2 \mathrm{mM} \mathrm{MgSO}{ }_{4}\right.$, $1 \times$ trace elements at $40^{\circ} \mathrm{C}$ ). Then spun down again and resuspended in $500 \mu \mathrm{L}$ of MA-I. The transformation mixture was prepared as follows: $20 \mu \mathrm{g}$ of the plasmid was diluted in $400 \mu \mathrm{L}$ of the MA-I buffer and mixed with 100 $\mu \mathrm{L}$ of cell suspension, subsequently, $500 \mu \mathrm{L}$ of $60 \%$ PEG $(w / v)$ was added to final PEG concentration of $30 \%(w / v)$. The transformation mixture was incubated for $5 \mathrm{~min}$ at room temperature, then transferred to $50 \mathrm{~mL}$ of warm MA2 medium and incubated overnight in normal growth conditions. The following day the culture was spun down in $40^{\circ} \mathrm{C}$ at 2,000 $\times \mathrm{g}$ for $5 \mathrm{~min}$ and resuspended in $50 \mathrm{~mL}$ of fresh MA2 medium to wash off the remaining PEG. The culture was led for 3 days in normal growth conditions before the selectable conditions were introduced. On the fourth day, chloramphenicol was added to the final concentration of $150 \mu \mathrm{g} \mathrm{mL}^{-1}$. The selectable growth of transformed C. merolae culture was conducted for a further three months. Every seven days C. merolae cells were spun down $\left(2,000 \times \mathrm{g}\right.$ for $5 \mathrm{~min}$ at $\left.40^{\circ} \mathrm{C}\right)$ and resuspended in fresh MA2 medium supplemented with chloramphenicol $\left(150 \mu \mathrm{g} \mathrm{mL}^{-1}\right)$. After 21 days, the concentration of chloramphenicol was increased up to $200 \mathrm{\mu g} \mathrm{mL}^{-1}$. Further, the $C$. merolae cells were plated with a sterile paint brush on Petri dishes with solid MA2 (0.4\% gellan gum) supplemented with chloramphenicol at the final concentration of $200 \mu \mathrm{g} \mathrm{mL}^{-1}$ and sealed with a triple layer of parafilm. Plates were incubated for at least four weeks until single colonies appeared. Single cell colonies (up to 10 colonies) were transferred to $20 \mathrm{~mL}$ flasks of MA2 medium with $200 \mu \mathrm{g} \mathrm{mL}^{-1}$ of chloramphenicol. The culture was led for several months with medium exchange every two weeks. In parallel, the same cultures were led in step-wise (extra $50 \mu \mathrm{g} \mathrm{mL}^{-1}$ for every step) increasing concentration of chloramphenicol.

\section{Cyanidioschyzon merolae growth rate}

All mutant strains and the wild-type (WT) were grown in a multicultuvator (PSI, Drasov, Czech Republic) and the grow-curves were recorded by the acquisition of the optic density at wavelengths of 680 and $720 \mathrm{~nm}$ at $30-\mathrm{min}$ intervals. Cells were illuminated with an intensity of 100 $\mu$ moles photon $\mathrm{m}^{-2} \mathrm{~s}^{-1}$ of external fluorescent light for 168 $\mathrm{h}$ (7 days) in a continuous flow of sterile air $0.5 \mathrm{~L} \mathrm{~min}^{-1}$ and $37^{\circ} \mathrm{C}$. Each curve was approximated with a sigmoidal function and the bending point was calculated as the time by which culture has reached half of the maximal optic density.

\section{SDS-PAGE and immunoblotting analysis}

Mutants and control cells were harvested by spinning down for $5 \mathrm{~min}$ at 2,000 $\times \mathrm{g}$ and resuspended in the resuspension buffer (20 mM Hepes-NaOH pH 7.6, 5 mM EDTA, and $330 \mathrm{mM}$ sucrose). Cells were counted in Neubauer chamber at least 3 times. Cells samples were solubilized in denaturing buffer ( $0.25 \mathrm{M}$ Tris- $\mathrm{HCl}[\mathrm{pH} 6.8], 0,4 \%(\mathrm{w} / \mathrm{v})$ sodium dodecyl sulfate, $10 \mathrm{M}$ urea, $2 \%$ (v/v) 2-mercaptoethanol and $20 \%(\mathrm{v} / \mathrm{v})$ glycerol) and mixed together in $1: 1(\mathrm{v} / \mathrm{v})$ ratio. Proteins were separated on $15 \%$ gels by Laemmli-type sodium dodecyl sulfate polyacrylamide gel electrophoresis (SDS-PAGE) method (Laemmli 1970). Gel wells were loaded with $10 \mu \mathrm{L}$ of cell lysate (obtained from $0.5 \times 10^{8}$ cells) and run under constant amperage $(24 \mathrm{~mA})$. Following electrophoresis, polypeptides were electro-transferred on PVDF-membrane (Towbin et al. 1979) and probed with rabbit anti-CAT (specific to CAT) antibodies (Sigma-Aldrich) or anti-D1 (Agrisera, Vännäs, Sweden). Bands specifically binding the probe were visualized by enhanced chemiluminescence method (SuperSignal West Pico; Thermo Scientific Inc.) according to standard procedures using ChemiDoc System (Bio-Rad).

\section{Southern blot analysis}

The transfer of the PstI digested DNA from the agarose gel to a nitrocellulose membrane was performed by a conventional alkaline method using $20 \times$ SSC buffer ( 3 $\mathrm{M} \mathrm{NaCl}, 0.3 \mathrm{M}$ sodium citrate, $\mathrm{pH}$ 7.0). DIG-labeled DNA fragments were prepared by PCR using DIG Probe Synthesis Kit (Roche, Basel, Switzerland) with specific primers (catgnF and catgnR hybridizing with the catgn sequence) and used as hybridization probes. The DIG was detected with alkaline phosphatase-conjugated anti-DIG antibody and CDP-Star (Roche). The signals were visualized with the luminescent image analyzer ChemiDoc XRS+ System (Bio-Rad). 

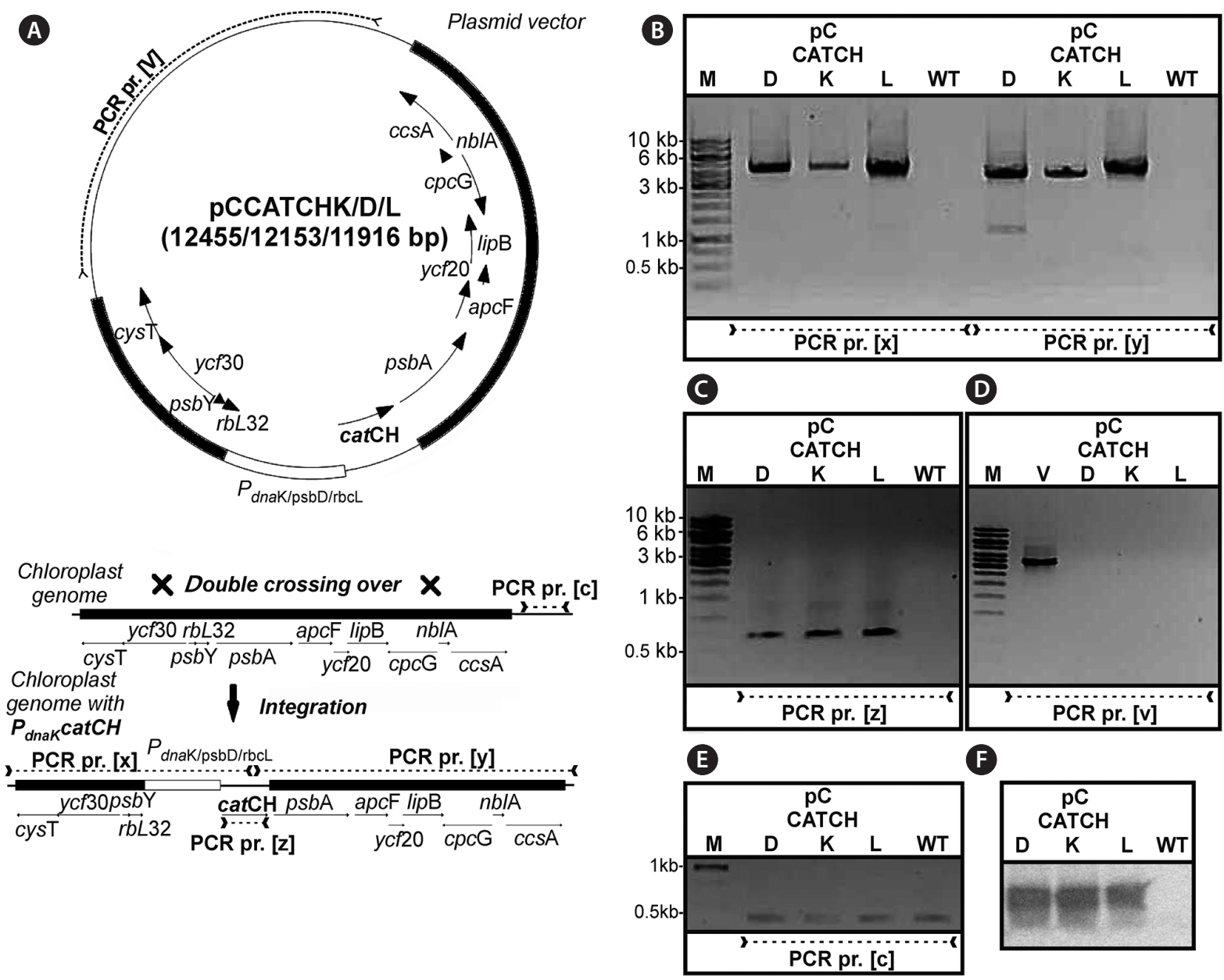

Fig. 1. Scheme of transformation vectors constructions and polymerase chain reaction (PCR) analysis of mutant strains. Vectors were constructed to facilitate integration into a region of the nuclear genome between $r b L 32$ and $p s b A$ genes (A). Integration of the resistance gene via double homologous recombination was confirmed by PCR of fragments beyond the introduced flanks and chloramphenicol acetyltransferase (cat) gene (B) in respective mutants ( $M$, marker; $D, P_{\text {psbD }} ; K, P_{\text {dnak }} ; L, P_{r b c} ; W T$, wild-type), the calculated lengths of PCR product are placed in the Supplementary Table S1. The presence of the cat gene (C), the absence of the vector remnants (D), control gene located beyond the homologous area $(E)$, and Southern blot of cat gene (F) performed on total genomic DNA, isolated from all mutants and the WT, digested with Pstl.

\section{Indirect immunofluorescence}

C. merolae cells were grown and synchronized by $8: 16$ $\mathrm{h}$ light : dark regime. Cell fixation and permeabilization were performed as described before (Zienkiewicz et al. 2017a). Primary and secondary antibodies were used at the following concentrations: $1: 100$ for rabbit anti-CAT antiserum, $1: 100$ for Alexa-488 goat anti-rabbit antibody (Thermo Fisher Scientific Inc.).

\section{Fluorescence microscopy}

Cells were observed using microscope Olympus BX43F (Tokyo, Japan) with a set of filters: "DAPI" 49025-
ET-DAPI/FluoroGold Longpass (Chroma, Bellows Falls, VT, USA) (excitation filter [EX] 300-400 nm, diachronic mirror $[\mathrm{DM}]>400 \mathrm{~nm}$, absorption filter $[\mathrm{BA}]>425 \mathrm{~nm}$ ) for blue fluorescence of DNA with Hoechst 33258 dye and red auto-fluorescence of chlorophyll at the same time. "Green/alexa anti-CAT" 49002-ET-EGFP (FITC/ Cy2) (Chroma) (EX 450-490 nm, DM > $495 \mathrm{~nm}$, BA 500$550 \mathrm{~nm}$ ) for green fluorescence of Alexa 488 goat antirabbit antibody, "RED/chlorophyll" 39106-AT-Qdot 625 (Chroma) (EX 400-450 nm, DM > $575 \mathrm{~nm}$, BA $590 \mathrm{~nm}$ ) for red auto-fluorescence of chlorophyll, FITC / TRITC (EX $475-490 \mathrm{~nm}, \mathrm{DM}>485 \mathrm{~nm}$, BA $610-640 \mathrm{~nm}$ ) for red autofluorescence of chlorophyll. 


\begin{tabular}{|c|c|c|c|c|c|c|c|}
\hline $23 \mathrm{~h}$ & $25 \mathrm{~h}$ & $23 \mathrm{~h}$ & $25 \mathrm{~h}$ & $23 \mathrm{~h}$ & $25 \mathrm{~h}$ & $23 \mathrm{~h}$ & $25 \mathrm{~h} 25 \mathrm{~h}$ \\
\hline $\mathrm{D}$ & $\mathrm{L}$ & $\mathrm{D}$ & $\mathrm{L}$ & $\mathrm{D}$ & $\mathrm{L}$ & $\mathrm{D}$ & $\mathrm{L}$ \\
\hline$w t$ & $w t$ & $d n a \mathrm{~K}$ & $d n a \mathrm{~K}$ & $p s b \mathrm{D}$ & $p s b \mathrm{D}$ & $r b c \mathrm{I}$ & $r b c \mathrm{~L} a p c \mathrm{C}$ \\
\hline
\end{tabular}

\section{Pro- moter \\ Anti- CAT}
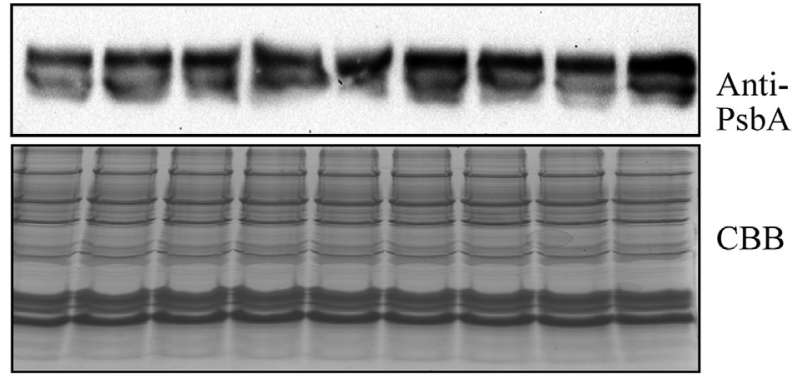

PsbA

CBB

Fig. 2. The mutant strains and the wild-type were grown for $48 \mathrm{~h}$ in photoperiod (6 L : $18 \mathrm{D}$ ). Then, after $15 \mathrm{~h}$ of darkness (D), as well as after $1 \mathrm{~h}$ of light (L) cells were harvested. An equal number of cells $\left(0.5 \times 10^{8}\right)$ were lysed and separated on $15 \%$ sodium dodecyl sulfate polyacrylamide gel electrophoresis, following western blot immunodetection of the overexpressed protein (chloramphenicol acetyltransferase [CAT]) as well as the control protein (psbA). Additionally, the nuclear apcC promoted CAT expression, as well as the CBB stained gel, were presented as quantity control.

\section{RESULTS \\ Construction of transformation vectors and transformation of Cyanidioschyzon merolae}

Selected promoter sequences were cloned into a transformation vector according to an established scheme (Fig. 1A). Correct introduction of promoter sequence was confirmed with basic genetic methods (Fig. 1B \& C). Correct clones were confirmed by PCR and Southern blot analysis (Fig. 1D-F). A set of primers, used for construction of transformation vectors was provided in Supplementary Table S1.

\section{The expression level of the exogenous protein}

To assess the strength of all chloroplast promoters we have visualized the concentration of the overexpressed protein CAT (CAT, catCH gene) by immunoblotting (Fig. 2). All cell lines were synchronized by 2-day growth-period 6 L : 18 D (Kanesaki et al. 2012). After 15 h of darkness and after $1 \mathrm{~h}$ of light, cells were harvested, lyzed and analyzed by SDS-PAGE electrophoresis followed by western
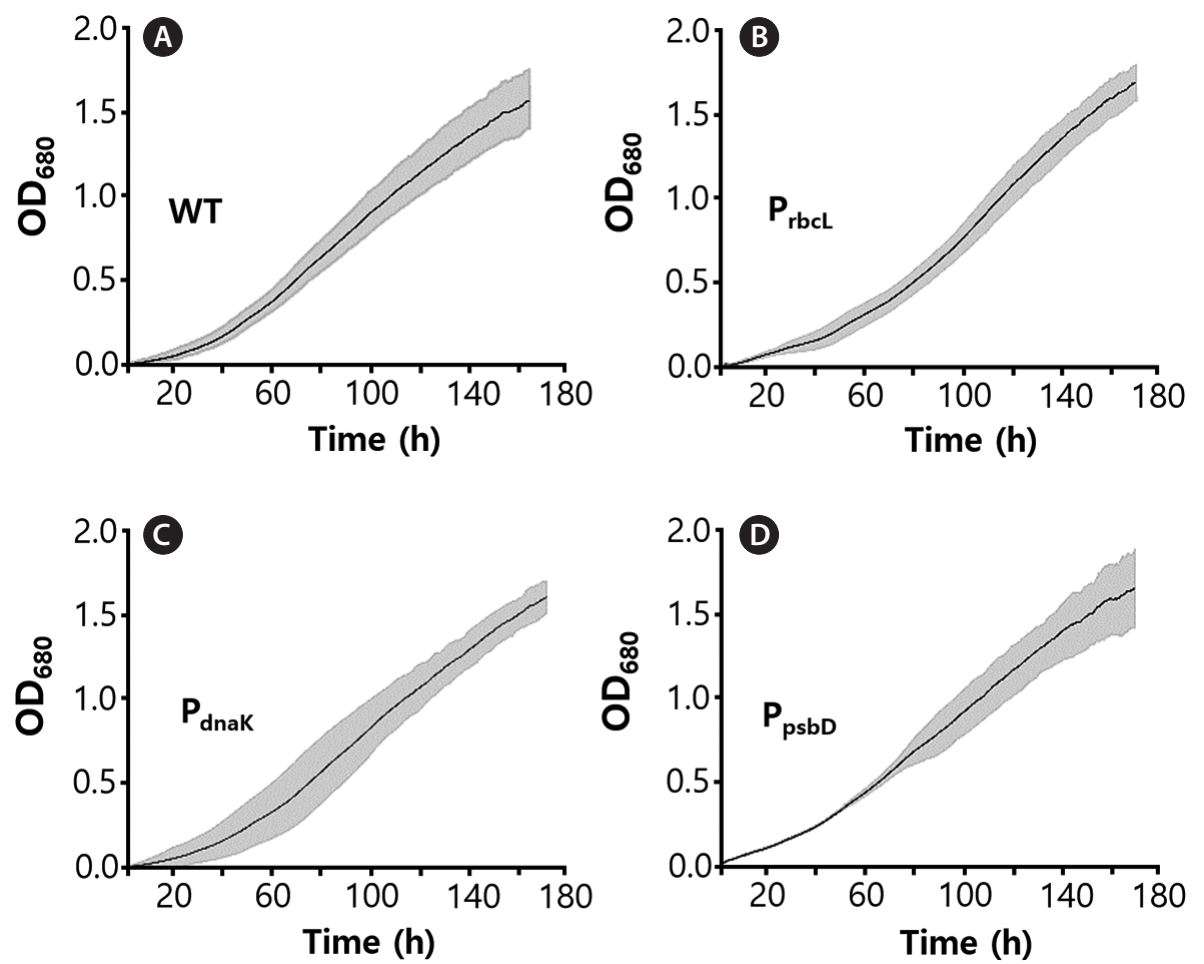

Fig. 3. Growth curves of three strains of modified Cyanidioschyzon merolae, expressing chloramphenicol acetyltransferase under selected promoters: $P_{\text {rbcl }}(B), P_{\text {dnak }}(C)$, and $P_{\text {psbD }}(D)$ as well as the wild-type (WT) (A). Mutants were cultivated in $200 \mu \mathrm{gL}^{-1}$ of chloramphenicol. All strains exhibit similar growth characteristics. Shaded area indicates standard deviation of the growth curve. 


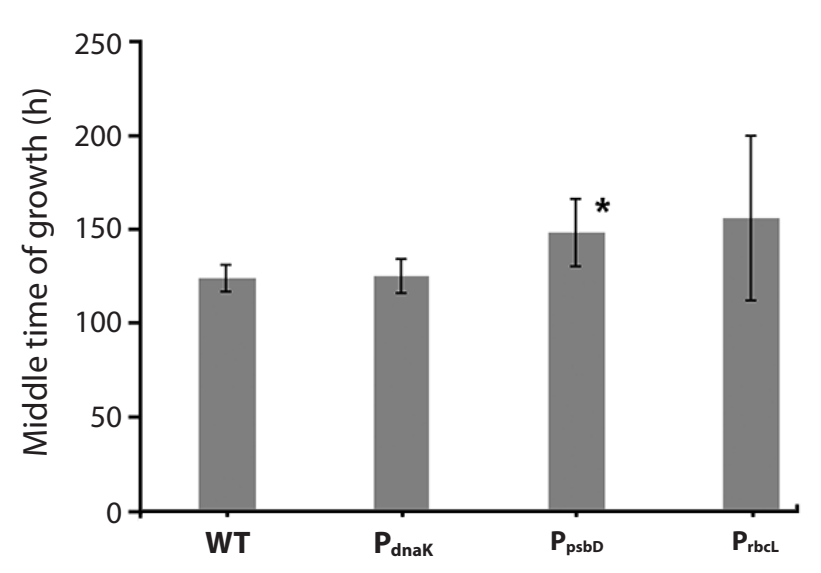

Fig. 4. Differences in growth rates between the three selected strains and the wild-type (WT). Growth curves were approximated with a sigmoidal function and the bending point (where the sigmoidal function reaches half of its maximal value) was taken as a measure of proliferation speed. The WT grew the fastest (130 \pm 7.7 h) together with $P_{\text {dnak }}$ promoted chloramphenicol acetyltransferase (CAT) $\left(132 \pm 9.1\right.$ h). The remaining $P_{\text {rbcl }}$ and $P_{p s b D}$ promoted CAT were insignificantly slower with $156 \pm 20$ and $165 \pm 45$ for $P_{r b c L}$ and $P_{p s b D}$ promoted CAT, respectively. The $\mathrm{P}_{\mathrm{rbcl}}$ exhibited statistically significant difference in the rate of growth, upon t-test analysis $\left({ }^{*} p<0.05\right)$ as compared to the WT. Mutants were cultivated in $200 \mathrm{\mu g} \mathrm{mL}^{-1}$ of chloramphenicol.

blotting. It was observed that the level of the CAT protein was present almost identical in all samples, independent of cell cycle or light irradiation.

\section{Growth dynamics}

C. merolae cell growth curves were recorded continuously for seven days at irradiation of $100 \mu$ moles photons $\mathrm{m}^{-2} \mathrm{~s}^{-1}$ in three repeats. It was observed that all mutants, as well as the WT, exhibited similar growth rate, suggesting that the resistance protein (CAT), expressed under all three promoters, provided complete protection from chloramphenicol (Fig. 3). All curves were approximated with a sigmoidal function and the bending point was calculated, as the time needed to achieve the maximal growth rate. It was observed that the WT cells, as well as all recombinant strains, grew at a nearly identical rate, achieving the bending point after $130 \mathrm{~h}$ (5.5 days) for the WT and up to $165 \mathrm{~h}$ (6.8 days) for the slowest (PsbD) strain (Fig. 4). The observed difference growth characteristic might be caused by metabolic exhaustion of mutant cells but it is likely to be insignificant. All mutants were grown $200 \mu \mathrm{g} \mathrm{mL}^{-1}$ chloramphenicol.

\section{Subcellular location of the overexpressed proteins}

To confirm chloroplast location of the expressed CAT protein, mutant cell-samples were labeled with anti-CAT antibody and further with the fluorescent secondary antibody. It was observed that green fluorescence of labeled CAT protein always overlapped red fluorescence of chlorophyll. Additionally, the blue fluorescence of chromatin was never overlapped with chlorophyll nor with CAT location (Fig. 5).

\section{DISCUSSION}

We have successfully transformed C. merolae chloroplast genome, according to the method described before (Zienkiewicz et al. 2017b), thereby confirming its applicability. All the selected mutant stains exhibited nearly identical growth rate (Figs $3 \& 4$ ), confirming sufficient, if not complete, protection of the chloroplast biosynthetic machinery by the CAT protein from the toxic effects of chloramphenicol (Zienkiewicz et al. 2017a).

All three proposed promoter sequences are capable of delivering a highly stable and efficient chloroplast protein synthesis. The chloroplast location of CAT expression was confirmed by indirect fluorescence microscopy (Fig. 5). Despite the fact that the $\mathrm{P}_{\mathrm{psbb}}$ promoter was reported to be highly dependent to light irradiation (Kanesaki et al. 2012), allowing for a highly variable transcription of the target protein RNA, the level of CAT protein remained unchanged independently of light irradiation (Fig. 2). Similarly, the cell-cycle dependent promoter $\mathrm{P}_{\mathrm{rbcL}}$ did not exhibit any depletion in CAT protein accumulation throughout the entire length of the photoperiod. The constitutive promoter $\mathrm{P}_{\text {dnak }}$ was capable of stable and efficient production of the CAT protein. Probably the CAT protein is stable enough to remain in chloroplast at a level capable of ensuring sufficient protection from chloramphenicol through the 24-h long cell cycle. It might be caused by the particular stability of the exogenous CAT protein, lower protein turn-over cycle in the chloroplast or exceptionally high level of CAT synthesis in selected mutants. The single-cell colony cultures were grown in a step-wise increased concentration of chloramphenicol, thereby allowing for selection of high CAT expressers. The sequence optimization was also likely to contribute to greater RNA stability and rates of transcription and translation (Daniel et al. 2015). The stability of CAT protein was comparable with the stability of D1 protein (Fig. 2 ), which was established before as exceptionally stable 


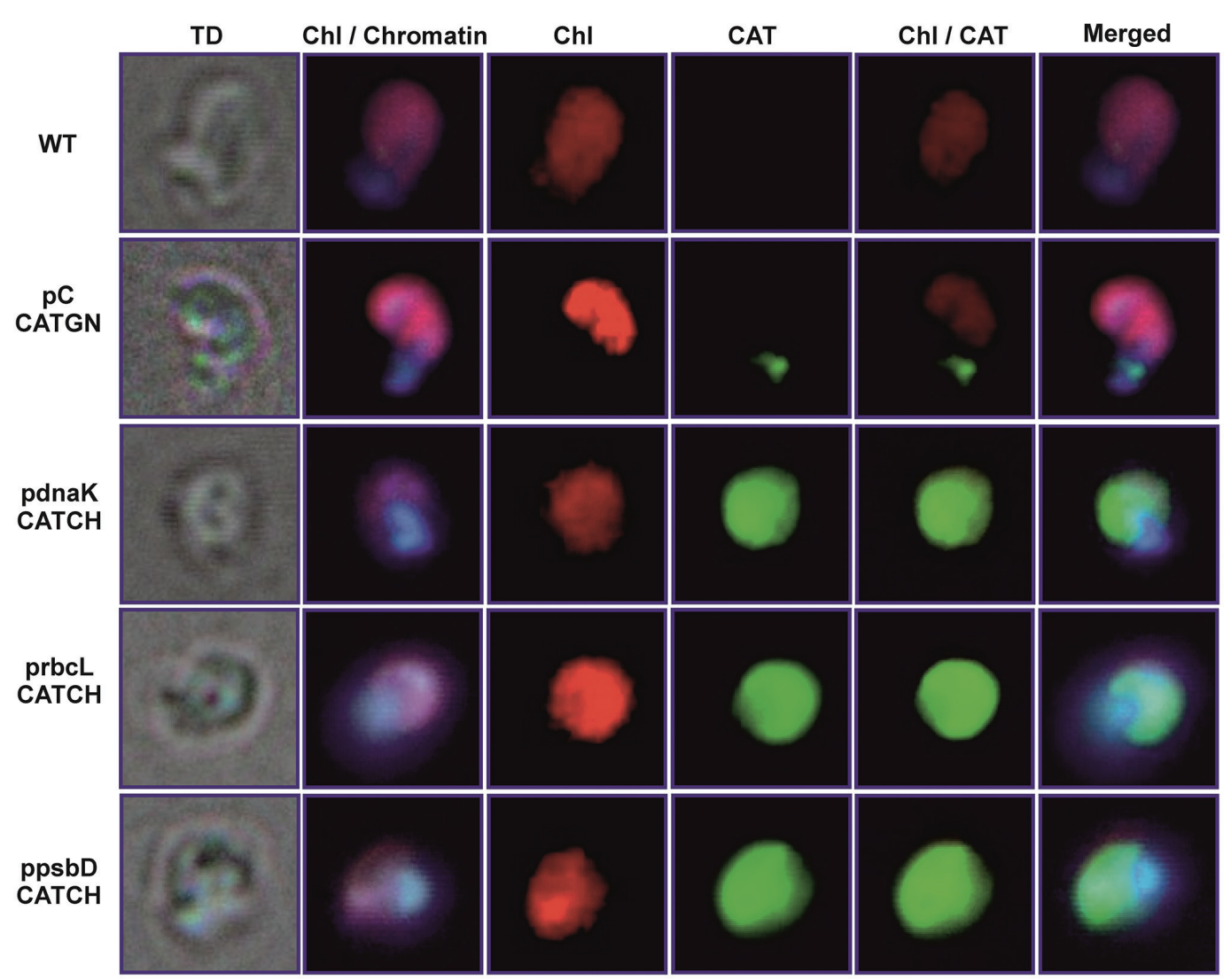

Fig. 5. Immunocytochemistry analysis of the stable chloroplast Cyanidioschyzon merolae cells, expressing chloramphenicol acetyltransferase (CAT) enzyme under selected promoters. Cells were permeated with the anti-CAT antibody and labeled with green fluorescent-dyed secondary antibody. Chromatin was visualized as blue fluorescence of Hoechst 33258 dye (Sigma-Aldrich, Munich, Germany). The natural emission of chlorophyll $a(\mathrm{Chl})$ was observed as red fluorescence. The stable nuclear transformant cells with cytoplasmic location of CAT (transformed with pC-CATGN) was used as a control, while the wild-type (WT) cells as the negative control. Cells were analyzed using a fluorescence microscope (Olympus BX43F, Tokyo, Japan). Strong green fluorescence of CAT protein was perfectly collocated with red fluorescence, stemming from the chlorophyll $a$ in all chloroplast-transformed cells. In case of the cytoplasm-located CAT nuclear variety, the green fluorescence was detected in cytoplasm. Additionally, blue fluorescence of chromatin never collocated with the fluorescence of chloroplast, allowing to confirm a reasonably high resolution of presented pictures. TD, transmitted light channel.

(Krupnik et al. 2013) when purified to homogeneity. The chloroplast located expression of CAT protein was, most likely, most efficient in the stroma, what ascertained best conditions of $\mathrm{pH}$ for CAT to function (optimum in $\mathrm{pH}$ 7.6-8, with $50 \%$ activity at $\mathrm{pH}<5$ and $>9$ ) (Thibault et al. 1980). This stability of the CAT protein had masked the modulatory property of inducible promoters $\left(\mathrm{P}_{\mathrm{psbD}}\right.$ and $\mathrm{P}_{\mathrm{rbcL}}$ ); however, variable level of RNA transcribed for the respective genes was investigated before (Kanesaki et al. 2012). The length of the promotor sequences was relatively long, therefore other promoters located on the sequence might influence the strength of selected promoters. Also, the transcription might be driven by an entirely different locus-related, upstream promoter, resulting in a read-through polycistronic transcription. A sufficiently strong, the constitutive upstream promoter could drive polycistronic transcription and mask the modulatory effect of inducible promoters. It might be necessary to include a transcription terminator upstream of the inducible promoter to attain entirely inducible transcription of genes of interest.

We conclude that all the three studied promoters are suitable for promoting the transcription of the selectable gene (like cat) since they can ascertain very high and stable level of the resistance protein. The ability to achieve modulated protein expression (induced by light irradiation or in a specific phase of the cell cycle) is probably dependent on the specific location and read-though promoters, the inherent stability of that protein and / or its compatibility with the chloroplast proteolytic machinery of C. merolae. 


\section{ACKNOWLEDGEMENTS}

This investigation was financed by Narodowe Centrum Nauki [Grant Opus 12 (2016/23/B/NZ1/00526)] awarded by the Polish National Science Centre to TK.

$\mathrm{MZ}$ and TK designed and carried out the research, interpreted the data and wrote the manuscript. WW and AD carried out SDS-PAGE and Western blot. ER analyzed data and revised the manuscript.

\section{SUPPLEMENTARY MATERIAL}

Supplementary Table S1. List of primers used in this study (http://www.e-algae.org).

\section{REFERENCES}

Bock, R. 2007. Plastid biotechnology: prospects for herbicide and insect resistance, metabolic engineering and molecular farming. Curr. Opin. Biotechnol. 18:100-106.

Daniel, E., Onwukwe, G. U., Wierenga, R. K., Quaggin, S. E., Vainio, S. J. \& Krause, M. 2015. ATGme: Open-source web application for rare codon identification and custom DNA sequence optimization. BMC Bioinformatics 16:303.

Daniell, H., Singh, N. D., Mason, H. \& Streatfield, S. J. 2009. Plant-made vaccine antigens and biopharmaceuticals. Trends Plant Sci. 14:669-679.

Hanahan, D. 1983. Studies on transformation of Escherichia coli with plasmids. J. Mol. Biol. 166:557-580.

Kanesaki, Y., Imamura, S., Minoda, A. \& Tanaka, K. 2012 External light conditions and internal cell cycle phases coordinate accumulation of chloroplast and mitochondrial transcripts in the red alga Cyanidioschyzon merolae. DNA Res. 19:289-303.

Krupnik, T., Kotabová, E., van Bezouwen, L. S., Mazur, R., Garstka, M., Nixon, P. J., Barber, J., Kaňa, R., Boekema, E. J. \& Kargul, J. 2013. A reaction center-dependent photoprotection mechanism in a highly robust photosystem II from an extremophilic red alga, Cyanidioschyzon merolae. J. Biol. Chem. 288:23529-23542.

Kuroiwa, T., Miyagishima, S., Matsunaga, S., Sato, N., Nozaki, H., Tanaka, K. \& Misumi, O. 2017. Cyanidioschyzon merolae: a new model eukaryote for cell and organelle biology. Springer, Singapore, $365 \mathrm{pp}$.

Laemmli, U. K. 1970. Cleavage of structural proteins during the assembly of the head of bacteriophage T4. Nature 227:680-685

Maliga, P. 2004. Plastid transformation in higher plants. Annu. Rev. Plant Biol. 55:289-313.

Minoda, A., Sakagami, R., Yagisawa, F., Kuroiwa, T. \& Tanaka, K. 2004. Improvement of culture conditions and evidence for nuclear transformation by homologous recombination in a red alga, Cyanidioschyzon merolae 10D. Plant Cell Physiol. 45:667-671.

Ohnuma, M., Yokoyama, T., Inouye, T., Sekine, Y. \& Tanaka, K. 2008. Polyethylene glycol (PEG)-mediated transient gene expression in a red alga, Cyanidioschyzon merolae 10D. Plant Cell Physiol. 49:117-120.

Sambrock, J., Fritsch, E. F. \& Maniatis, T. 1989. Molecular cloning: a laboratory manual. 2nd ed. Cold Spring Harbor Laboratory Press, Cold Spring Harbor, 1546 pp.

Shaw, W. V. \& Unowsky, J. 1968. Mechanism of R factor-mediated chloramphenicol resistance. J. Bacteriol. 95:19761978.

Thibault, G., Guitard, M. \& Daigneault, R. 1980. A study of the enzymatic inactivation of chloramphenicol by highly purified chloramphenicol acetyltransferase. Biochim. Biophys. Acta 614:339-342.

Towbin, H., Staehelin, T. \& Gordon, J. 1979. Electrophoretic transfer of proteins from polyacrylamide gels to nitrocellulose sheets: procedure and some applications. Proc. Natl. Acad. Sci. 76:4350-4354.

Zienkiewicz, M., Krupnik, T., Drożak, A., Golke, A. \& Romanowska, E. 2017a. Chloramphenicol acetyltransferase: a new selectable marker in stable nuclear transformation of the red alga Cyanidioschyzon merolae. Protoplasma 254:587-596.

Zienkiewicz, M., Krupnik, T., Drożak, A., Golke, A. \& Romanowska, E. 2017b. Transformation of the Cyanidioschyzon merolae chloroplast genome: prospects for understanding chloroplast function in extreme environments. Plant Mol. Biol. 93:171-183.

Zienkiewicz, M., Krupnik, T., Drożak, A., Wasilewska, W., Golke, A. \& Romanowska, E. 2018. Deletion of $p s b Q$ ' gene in Cyanidioschyzon merolae reveals the function of extrinsic PsbQ' in PSII. Plant Mol. Biol. 96:135-149. 